\title{
Effect of defined, seasonally variable exercise on oxidative status markers (TOS, TAS) in jumping horses
}

\author{
HANNA BIS-WENCEL, AGNIESZKA ROWICKA, AGNIESZKA KUBIK-KOMAR*, \\ HENRYK KRUKOWSKI, BOŻENA NOWAKOWICZ-DĘBEK, ŁUKASZ WLAZŁO

\begin{abstract}
Department of Animal Hygiene and Environmental Hazards, Faculty of Animal Science and Bioeconomy, University of Life Sciences in Lublin, Akademicka 13, 20-950 Lublin, Poland

*Department of Applied Mathematics and Computer Science, Faculty of Production Engineering, University of Life Sciences in Lublin, Głęboka 28, 20-612 Lublin, Poland
\end{abstract}

Bis-Wencel H., Rowicka A., Kubik-Komar A., Krukowski H., Nowakowicz-Dębek B., Wlazło $Ł$. Effect of defined, seasonally variable exercise on oxidative status markers (TOS, TAS) in jumping horses

Summary

The present study aimed to determine the adaptation capacity of horses subjected to defined, seasonally variable exercise on the basis of selected indicators of their oxidative status. The research was carried out over a two-year period on 25 Polish Noble Half-bred horses (PKSP). All horses came from stables in south-eastern Poland $\left(5^{\circ} 15^{\prime} 00^{\prime} \mathrm{N}, 2^{\circ} 34^{\prime} 00^{\prime \prime} \mathrm{E}\right)$ and competed in show jumping. According to the intensity of exercise, two experimental periods were distinguished, characterized by moderate intensity of exercise (D1) and high intensity of exercise (D2). The test material consisted of blood taken from the external jugular vein into dry tubes in a closed system. Samples were collected four times. The oxidative status was determined by means of PerOx reagents (TOS/TOC) and ImAnOx reagents (TAS/TAC) from Immundiagnostik. The results were analyzed statistically with the Statistica 10 software (StatSoft Inc.). Changes were found in all parameters studied. The average level of total antioxidant status (TAS) in our research was low, and the average level of total oxidant status (TOS) obtained in the experiment corresponds to a low level of oxidative stress. The oxidant status and the antioxidant status did not correlate with each other. The values were balanced regardless of sex or age, which suggests that training did not result in oxidative stress. Our results also suggest that evaluation of blood oxidative markers can help in assessing the welfare of training horses.

Keywords: horses, oxidative stress, blood, exercise

Show jumping is one of the most popular equestrian disciplines shown in the media $(18,37)$. It has also been the most dynamically developing equestrian discipline in Poland in recent years. About $70 \%$ of all registered competitors participate in show jumping (33). More and more Polish Noble Half-bred horses are used in competitions. However, international competitions and enormous financial outlays for the development of the discipline of show jumping are a big challenge. Therefore, despite strict specialization in the breeding of jumping horses, contestants, trainers and breeders are always looking for horses predisposed to compete in this discipline (37). Nowadays, equestrian disciplines are characterized by a high degree of specialization, requiring specific breeding aimed at achieving the qualities necessary for outstanding sports results $(20,33)$. As the equestrian sport became increasingly popular in the early 1970 s, a lot of Hanoverian and French Anglo-Arab horses were used in breeding to improve Polish horses. The sports crossbreds were included in the second part of the Studbook in the 1980s and later. In 1997, the first Studbook for a new crossbred sports horse (SP) was initiated. The Polish Noble Half-bred horse was created in response to demand for high-performance horses, adapted to various equestrian disciplines, such as show jumping, dressage, and WKKW (eventing/horse trials) (25).

Ensuring the well-being of training horses that participate in different competitions is a priority. Continuous training is a challenge for the body's oxidative status. It is well known that too intensive exercise can lead to oxidative stress due to overtraining. Moreover, many studies provide rational support for the claim that physical exercise increases the production of reactive oxygen species (ROS) $(6,17,30,39$, 40). Damage of tissues and cell organelles resulting from oxidative stress has been proven in research on people engaged in exercise (43). Concrete and tangible 
evidence of oxidative stress associated with exercise was also found in livestock, including horses. It seems important that a significant part of research in this field has been done on horses, with regard to exercise physiology $(7,23)$.

The aim of the study was to assess the impact of seasonally variable, intense exercise on the variability of selected oxidative blood parameters of Polish Noble Half-bred jumping horses and to investigate the adaptation of horses subjected to defined exercise.

\section{Material and methods}

The research was carried out over a two-year period on 25 Polish Noble Half-bred horses, 13 mares and 12 geldings, aged 4-13 years (BW $458 \pm 20 \mathrm{~kg}$, BCS 5). The horses were located in stables in south-eastern Poland $\left(51^{\circ} 15^{\prime} 00^{\prime \prime} \mathrm{N}\right.$, $\left.22^{\circ} 34^{\prime} 00^{\prime \prime} \mathrm{E}\right)$ and all of them competed in show jumping. Research on the animals was conducted according to the ethics committee on animal use ( $\mathrm{Nr} 14 / 2010)$.

The horses were kept in individual stalls, and water was provided ad libitum throughout the experiment. In winter, feeding was based on full commercial feeds. Moreover, the horses received oats per diem (according to nutritional requirements of horses), hay, salt licks, as well as $60 \mathrm{~g}$ of vitamin B and vitamin E in the form of HippVital preparation. In the summer season, the daily feeding dose per horse was $3.5 \mathrm{~kg}$ of hay, $5 \mathrm{~kg}$ of oats (in two doses) and $60 \mathrm{~g}$ of vitamin B (HippVital). The horses also received $400 \mathrm{~g}$ of crushed corn and $2 \mathrm{~kg}$ of carrot at noon. During competitions, the horses were additionally fed with muesli (Dynamix from Besterly) twice a day, $1 \mathrm{~kg}$ per horse.

The horses were under constant veterinary supervision and were subjected to preventive measures in accordance with a program applicable to this animal species. The animals participated in a daily training program, which comprised $1 \mathrm{~h}$ on a carousel, $10 \mathrm{~min}$ of walking, $10 \mathrm{~min}$ of relaxed trot, 5 min of working trot, and 5-7 min of galloping. Jumping training took place twice a week and consisted of 35-45 jumps for each horse. During competitions, the training plan also included an additional 1 hour of lunging and 1 hour of riding in the riding arena (under the saddle) in the morning. Because of the variable intensity of exercise for horses in the experiment, two experimental periods were distinguished, characterized by moderate intensity of exercise (D1) and high intensity of exercise (D2).

In order to determine the dependence of oxidative stress on age, two age groups were formed: younger horses (aged 4-8 years, $\mathrm{n}=12$ ) and older horses (aged 9-13 years, $n=13$ ). The test material consisted of blood taken from the external jugular vein into dry tubes in a closed system, in the morning, before feeding and watering. Blood samples were collected four times: twice during exercise of moderate intensity (D1) (in early March and late May) and twice during exercise of high intensity (D2) (in October and early December).

Blood for measurement of total oxidative status was centrifuged at $1,500 \times \mathrm{g}$ for 15 minutes, and serum was separated. The assessment of total oxidative status is based on the close correlation between oxygen radicals and fatty acid peroxides formed in the lipid peroxidation process. This relationship makes it possible to determine and characterize the oxidative status in biological fluids, taking into account the potential occurrence of oxidative stress. Peroxide was assessed on the basis of the peroxidase reaction with peroxides found in the sample, followed by the conversion of TMB into a colored product. After addition of the holding solution, the samples were examined in an ELISA reader (Microtiter) at $450 \mathrm{~nm}$. Quantification was done with the calibrator included. The intra-assay coefficient was $2.94 \%$ $(162 \mu \mathrm{mol} / 1)$ for $\mathrm{n}=6$, and the inter-assay coefficient was $6.63 \%(136 \mu \mathrm{mol} / \mathrm{l})$ and $6.85 \%(389 \mu \mathrm{mol} / \mathrm{l})$ for $\mathrm{n}=10$. The above-mentioned determinations were made with a set of PerOx reagents (TOS/TOC) from Immundiagnostik.

The test material for determination of total antioxidative status was collected in the same way, and the same procedure was used to prepare serum. The total antioxidative potential in serum was determined by the antioxidant reaction in the sample with a defined amount of exogenously supplied hydrogen peroxide $\left(\mathrm{H}_{2} \mathrm{O}_{2}\right)$. Antioxidants in the sample eliminate a specific amount of hydrogen peroxide. The remaining $\mathrm{H}_{2} \mathrm{O}_{2}$ level is calculated photometrically by an enzymatic reaction that uses TMB conversion to a colored product. After addition of the holding solution, samples are examined at $450 \mathrm{~nm}$ in an ELISA reader (Microtiter). Quantification is performed with the calibrator provided, and the difference between the concentrations of peroxide applied and calculated at a given time is proportional to antioxidant reactivity in the sample (antioxidant capacity). The intra-assay coefficient amounted to $3.99 \%(213 \mu \mathrm{mol} / \mathrm{l})$ and $2.04 \%(308 \mu \mathrm{mol} / \mathrm{l})$ at $\mathrm{n}=12$. The coefficient of inter-assay variation was $2.65 \%(217 \mu \mathrm{mol} / \mathrm{l})$ and $3.89 \%(285 \mu \mathrm{mol} / \mathrm{l})$ for $\mathrm{n}=12$. The above determinations were made with an ImAnOx reagent set (TAS/TAC) from Immundiagnostik.

The results obtained were analyzed statistically with the Statistica 10 software (StatSoft Inc.).

This paper presents descriptive statistics and verified hypotheses about the equality of means between the two experimental periods. To verify these hypotheses, multivariate analysis of variance (MANOVA) was used for two factors of repeated measurements. In addition, it was checked whether there were statistically significant differences between the means for horses of different sexes or ages during the experiment and with the increasing intensity of training. The data were also verified by a one-dimensional F test for repeated measurements with the Huynh-Feldt corrections (H-F) for degrees of freedom. In the case of rejection of the null hypothesis (of the equality of the means), Tukey's test of multiple comparisons was performed. Then, linear dependences of TOS (total oxidative status) and TAS (total antioxidant status) were examined using Pearson's correlation coefficient. The threshold indicating the existence of dependence between features was accepted as 0.6. The final results were given in a tabular form or presented in the form of figures. For all statistical tests, the significance level was $\alpha=0.05$.

In this case, successive response measurements made over time or space are considered as correlated dependent variables. That is, observations for each level of withinsubject factor (time/space) is presumed to be a different dependent variable. 
In the notation of matrices, the general linear model of the experiment with measurements made in time or space is the same as the model without repeated measurements and might be described as follows: $\mathrm{Y}=\mathrm{XB}+\mathrm{E}$, where $\mathrm{Y}$ is the matrix of observations, $\mathrm{X}$ is the design matrix, $\mathrm{B}$ are the model parameters, and $\mathrm{E}$ is the errors matrix. The difference between these two models is in the matrix B, which, in addition to treatment effects, includes the effects of time points or space levels. Then, in order to check whether experimental factors have a significant influence on the difference between the mean values of the variable, the null hypothesis $\mathrm{H}_{0}: \mathrm{LBM}=0$ should be verified against the alternative one $\mathrm{H}_{1}$ : $\mathrm{LBM} \neq 0$, where the contrast matrix $\mathrm{L}$ describes the linear combination of experimental factor (sex and age) parameters, and $\mathrm{M}$ describes the linear combination of the parameters connected with repeat measures (experimental groups).

\section{Results and discussion}

Statistically significantly lower values of the average TOS level were noted in the period of intensive exercise (D2) compared with the period of moderate exercise (D1) $\mathrm{p}=0.00135$ (Tab. 1). Moreover, statistically significant lower values were noted in geldings. Younger horses were characterized by slightly higher values of TOS $(149.81 \mu \mathrm{mol} / \mathrm{l})$ than older horses $(147.87 \mu \mathrm{mol} / \mathrm{l})$ (Tab. 1). However, the above-mentioned tendency was observed only in the period D2 (Tab. 2). During moderate exercise (D1), higher TOS values were noted in older horses (Tab. 2, Fig. 1). Horses of both sexes and both age groups were characterized by a downward tendency of TOS during intensive exercise (D2) (Tab. 2, Fig. 1). The average level of total oxidative status (TOS) ranged from 126.97 to 187.98 ( $\mu \mathrm{mol} / \mathrm{l})$ (Tab. 2), which, according to the manufacturer of the test, indicates a low level of oxidative stress. The lowest values were obtained in geldings during the D2 period and the highest in mares during the D1 period (Tab. 2, Fig. 1). In terms of the intensity of exercise, statistically significant differences were found in mares between periods D1 and D2 ( $p=0.001521)$ (Tab. 3). Statistically significant differences related to the intensification of exercise were also recorded between mares and geldings during the D1 period $(p=0.002096)$ and between mares during the D1 period and geldings during the D2 period $(\mathrm{p}=0.000216)($ Tab. 3).

The average level of total antioxidant status (TAS) ranged from 270.81 to $314.74 \mu \mathrm{mol} / 1$ (Tab. 2), which indicates a low antioxidant potential. The lowest values were recorded in younger horses during the D1 period, and the highest in older horses during the same experimental period (Tab. 2, Fig. 1). In both sexes, the higher TAS level was observed during intensive exercise (D2) (Tab. 2, Fig. 1), while in the age groups, the higher TAS
Tab. 1. Basic descriptive statistics for oxidative status markers $(n=25)$

\begin{tabular}{|c|c|c|c|c|c|c|c|}
\hline \multirow{2}{*}{\multicolumn{2}{|c|}{ Markers }} & \multicolumn{2}{|c|}{ Period } & \multicolumn{2}{|c|}{ Age } & \multicolumn{2}{|c|}{ Sex } \\
\hline & & \multirow{2}{*}{$\frac{\text { D1 }}{165.31^{\mathrm{a}}}$} & \multirow{2}{*}{$\frac{\mathrm{D} 2}{132.60^{\mathrm{b}}}$} & \multirow{2}{*}{$\begin{array}{c}\text { Younger } \\
149.81\end{array}$} & \multirow{2}{*}{$\frac{\text { Older }}{147.87}$} & \multirow{2}{*}{$\frac{\text { Geldings }}{133.86^{c}}$} & \multirow{2}{*}{$\frac{\text { Mares }}{162.89^{d}}$} \\
\hline \multirow{4}{*}{$\mathrm{TOS}(\mu \mathrm{mol} / \mathrm{l})$} & Mean & & & & & & \\
\hline & Statistical error & 9.27 & 2.73 & 7.01 & 7.90 & 6.19 & 5.95 \\
\hline & $-95 \%$ & 146.16 & 126.96 & 135.30 & 131.51 & 121.04 & 150.58 \\
\hline & $+95 \%$ & 184.45 & 138.24 & 164.31 & 164.23 & 146.67 & 175.20 \\
\hline \multirow{4}{*}{ TAS $(\mu \mathrm{mol} / \mathrm{l})$} & Mean & 290.14 & 294.56 & 291.83 & 293.01 & 298.94 & 286.94 \\
\hline & Statistical error & 14.90 & 14.19 & 13.77 & 15.54 & 14.78 & 14.20 \\
\hline & $-95 \%$ & 259.37 & 265.25 & 263.32 & 260.85 & 267.61 & 257.55 \\
\hline & $+95 \%$ & 320.91 & 323.86 & 320.33 & 325.17 & 328.80 & 316.33 \\
\hline
\end{tabular}

Explanations: $\mathrm{a}, \mathrm{b}, \mathrm{c}, \mathrm{d}-$ means with different superscript letters differ significantly at $\mathrm{p} \leq 0.05$

Tab. 2. Mean values of oxidative status markers in younger and older horses and in mares and geldings in the two experimental periods $(n=25)$

\begin{tabular}{|c|c|c|c|c|c|c|c|c|c|}
\hline \multirow{2}{*}{\multicolumn{2}{|c|}{ Markers }} & \multicolumn{2}{|c|}{ Younger } & \multicolumn{2}{|c|}{ Older } & \multicolumn{2}{|c|}{ Mares } & \multicolumn{2}{|c|}{ Geldings } \\
\hline & & D1 & D2 & D1 & D2 & D1 & D2 & D1 & D2 \\
\hline \multirow{4}{*}{ TOS $(\mu \mathrm{mol} / \mathrm{l})$} & Mean & 164.61 & 135.00 & 166.19 & 129.54 & 187.98 & 137.80 & 140.75 & 126.97 \\
\hline & Statistical error & 12.66 & 3.65 & 14.28 & 4.12 & 11.23 & 3.54 & 11.69 & 3.68 \\
\hline & $-95 \%$ & 138.42 & 127.44 & 136.64 & 121.02 & 164.74 & 130.47 & 116.56 & 119.34 \\
\hline & $+95 \%$ & 190.81 & 142.56 & 195.74 & 138.07 & 211.21 & 145.13 & 164.93 & 134.59 \\
\hline \multirow{4}{*}{ TAS $(\mu \mathrm{mol} / \mathrm{l})$} & Mean & 270.81 & 312.85 & 314.74 & 271.28 & 286.88 & 287.00 & 293.67 & 302.74 \\
\hline & Statistical error & 19.42 & 18.50 & 21.91 & 20.88 & 21.09 & 19.98 & 21.95 & 20.80 \\
\hline & $-95 \%$ & 230.63 & 274.56 & 269.41 & 228.08 & 243.24 & 245.66 & 248.24 & 259.71 \\
\hline & $+95 \%$ & 310.99 & 351.14 & 360.07 & 314.47 & 330.52 & 328.34 & 339.09 & 345.77 \\
\hline
\end{tabular}

level was noted during the D1 period (Tab. 2). Conversely, in younger horses the higher TAS level was noted in the D2 period (312.85 $\mu \mathrm{mol} / 1$ ) (Tab. 2), and statistically significant differences were observed between age and intensity of training at $\mathrm{p}=0.04018$. A higher level of total antioxidant status was also observed in geldings. However, the differences were not statistically significant (Tab. 1).

Horses, as extraordinary athletes, are bred for high levels of physical activity. Unfortunately, even in horses, strenuous exercise and chronic, exhausting effort can cause stress, which can have a detrimental effect on the body $(1,5)$. 


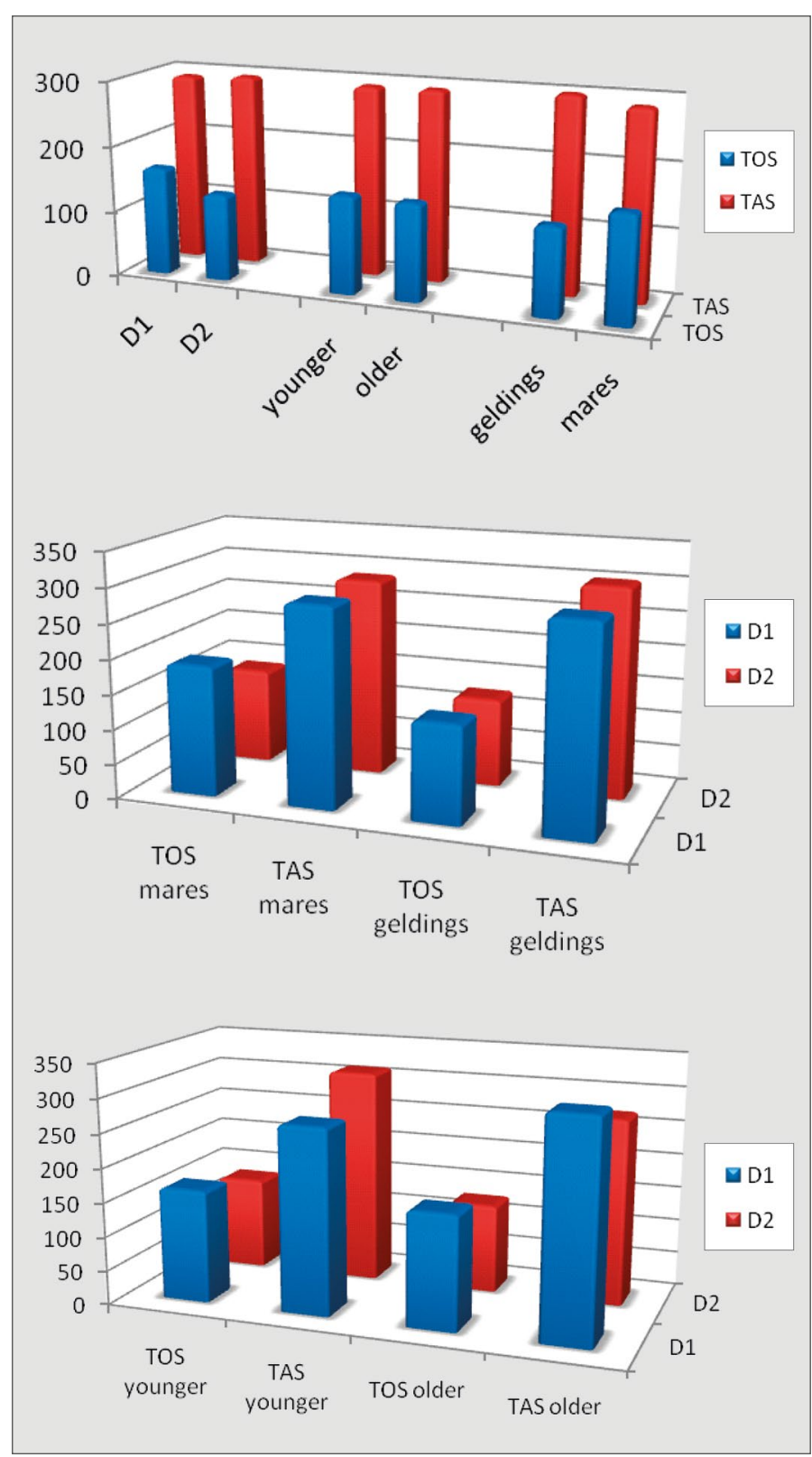

Fig. 1. Mean values of oxidative status markers TOS and TAS $(\mu \mathrm{mol} / \mathrm{l})$ for horses of different sexes and ages in the two experimental periods $(n=25)$

Tab. 3. Statistically significant differences in oxidation status in mares and geldings in the two experimental periods $(n=25)$

\begin{tabular}{|c|c|c|c|c|c|}
\hline \multirow{3}{*}{\multicolumn{2}{|c|}{ Periods }} & \multicolumn{4}{|c|}{ TOS ( $\mu \mathrm{mol} / \mathrm{l})$} \\
\hline & & \multicolumn{2}{|c|}{ Mares } & \multicolumn{2}{|c|}{ Geldings } \\
\hline & & D1 & D2 & D1 & D2 \\
\hline \multirow{2}{*}{ Mares } & D1 & & 0.001521 & 0.002096 & 0.000216 \\
\hline & D2 & 0.001521 & & 0.995094 & 0.813315 \\
\hline \multirow{2}{*}{ Geldings } & D1 & 0.002096 & 0.995094 & & 0.671399 \\
\hline & D2 & 0.000216 & 0.813315 & 0.671399 & \\
\hline
\end{tabular}

Explanation: $\mathrm{p}<0.05$

Evidence of stress-related oxidative stress in horses has been described in reports on intense exercise (48) and endurance rallies (28). Thousands of years of selective breeding for speed and endurance, have made the maximum horsepower in horses 3.5 times as high as the one predicted by the general allometric equation (42). At speeds of around 10.5 and $16 \mathrm{~m} / \mathrm{s}$ during the long and short run, respectively, the horse is one of the fastest animals with four limbs on Earth (32).

During the maximum physical effort, the consumption of oxygen by horses increases 40 times (24). This increased consumption is associated with production of free radicals and may lead to oxidative stress $(2,9,48)$. Despite evidence that exercise in horses and humans is a pro-inflammatory factor, the relationship between disruption of the prooxidant-antioxidant balance and poorer sports results has not yet been well established (10). Horses subjected to prolonged periods of high oxygen intake are at risk of prooxidant-antioxidant imbalance. This has been confirmed in studies that show an increase in post-exercise oxidation markers in rally horses (19).

The induction of oxidative stress in this species may depend on factors such as diet, disease, duration and intensity of exercise, or fitness level (12). Reasonable physical training counteracts many physiological processes resulting from aging as well as the high rate of ROS production.

Overly intensive training may contribute to the risk of diseases resulting from excessive oxidative stress and plays a role in the pathogenesis of many diseases, including joint diseases, colic, and endotoxemia (8, $14,35,45)$. It has been proved that the high production of ROS during exhaustive exercise contributes to cell damage, lipid peroxidation, protein oxidation, and disintegration of DNA, which consequently leads to the loss of cellular integrity $(15,23,26,34,47)$. Numerous studies confirm that excessive, exhausting training causes oxidative stress $(4,6,30,31,36,40,41,46)$. This fact has also been noted in athletes participating in training and sports competitions (17). Defensive antioxidant mechanisms may counteract the formation of oxygen radicals. Vitamin E and micronutrient supplementation improve the antioxidant capacity of blood $(2,11,13,48)$. However, no studies have shown a clear effect of antioxidant supplementation on horse's performance. It is known that antioxidant requirements are higher in athletes compared to people who live a normal lifestyle $(10,27)$ and that antioxidant supplementation decreases post-workout oxidative stress without causing a measurable increase in performance (10). Imbalance between these mechanisms and the production of oxidation reactants leads to oxidative stress (1). Nevertheless, regular exercise causes the body to adapt to high concentrations of oxidants and thus improves athletic performance (8). It is assumed that the total antioxidant status (TAS) is a summary measure of the ability to neutralize free radicals (38). It means that this parameter is the sum of the activity of all antioxidants present in serum. Many authors believe that, in addition to measuring the activity of individual enzymes protecting the organism from reac- 
tive oxygen species and the concentration of individual low-molecular antioxidants, it is also important to evaluate the efficiency of the entire antioxidant system in tissues, organs, and body fluids. This is because potential interaction between individual components of the antioxidant system in vivo makes the values of individual compounds less representative than the total antioxidant capacity $(29,38)$. In addition, it is impossible to measure the levels of all antioxidants in serum, because some of them have not yet been identified (44). Therefore, the total antioxidant capacity is a fairly important parameter that should be taken into account in studies on the body's balanced state and disturbances between antioxidants and pro-oxidants.

The vast number of antioxidants in fluids and tissues in humans and animals makes the measurement of particular antioxidants difficult. That is why several methods have been developed to measure the value corresponding to the amount of all antioxidants: TAS. However, changes in antioxidant capacity are difficult to interpret because it can increase as a result of nutritional effects or because of adaptation to oxidative stress (16). At this point, one should also pay attention to the individual variability of the animals studied, which can significantly affect the statistics.

The average level of total antioxidant status (TAS) in our research was low. The values obtained in the experiment were balanced regardless of the sex or age group. With the intensification of exercise, the TAS levels in older horses decreased. This is in line with findings of Balogh et al. (3) who conducted experiments on a group of 5 mares, 7 stallions, and 2 geldings and calculated average values. In our research, intense exercise (D2) was associated with an increase in TAS values in younger horses. A similar tendency was observed by Kędzierski et al. (21). Those authors performed 2 cardiac stress tests over 4 months and showed that the level of TAS increased along with the increasing intensity of exercise. The increase in total antioxidant potential was not statistically significant, similarly to our research.

The average level of total oxidant status (TOS) corresponds to the low level of oxidative stress. Similarly, no evidence of oxidative stress was found in horses after a $140 \mathrm{~km}$ endurance race at high temperature (28). Nonetheless, evidence of oxidative stress and minor muscle damage was found in trotters exposed to exercise of moderate intensity and duration (22). Therefore, it seems that the monitoring of TOS during training sessions can be very useful in determining the welfare of horses engaged in exercise. There are studies on other animal species that show oxidative stress in connection with metabolic processes, but few deal with oxidative stress in the context of exercise.

The oxidant status and the antioxidant status did not correlate with each other, which seems to confirm the research hypothesis and confirms the occurrence of an adaptive oxidative stress. The scale of oxidative stress resulting from the individual variability of horses reflected the positive effect of exercise. This may indicate the possibility of stimulating the adaptation of the body through training according to a properly designed plan.

Intensification of exercise triggered minor changes in all parameters tested. The decrease in TOS in the group D2 appeared irrespective of sex or age. It seems that oxidative markers are valuable in assessing the welfare of training horses. As already mentioned, the total antioxidant status is a fairly important parameter that should be taken into account in research on the body's balanced state and disturbances between antioxidants and pro-oxidants. Therefore, it seems reasonable to include markers of oxidative status in monitoring the welfare of horses during training and competitions.

\section{References}

1. Art T., Lekeux P.: Exercise-induced physiological adjustments to stressful conditions in sports horses. Liv. Prod. Sci. 2005, 92, 101-111.

2. Avellini L., Chiaradia E., Gaiti A.: Effect of exercise training, selenium and vitamin $\mathrm{E}$ on some free radical scavengers in horses (Equus caballus). Comp. Biochem. Physiol. B 1999, 123, 147-154.

3. Balogh N., Gaál T., Ribiczeynè P. S., Petri Á.: Biochemical and antioxidant changes in plasma and erythrocytes of pentathlon horses before and after exercise. Vet. Clin. Pathol. 2001, 30, 214-218.

4. Belviranl M., Gokbel H.: Acute exercise induced oxidative stress and antioxidant changes. Europ. J. Gen. Medicine 2006, 3, 126-131.

5. Bis-Wencel H.: Long-term exercise and its effect on selected haematological indices of blood in jumping horses. Zeszyty Naukowe Uniwersytetu Przyrodniczego we Wrocławiu. Biol. Hod. Zw. 2011, 63, 79-87.

6. Bloomer R. J., Smith W. A.: Oxidative stress in response to aerobic and anaerobic power testing: Influence of exercise training and carnitine supplementation. Res. Sports Medicine 2009, 17, 1-16.

7.Bottegaro N. B., Gotić J., Šuran J., Brozić D., Klobučar K., Bojanić K., Vrbanac Z.: Effect of prolonged submaximal exercise on serum oxidative stress biomarkers (d-ROMs, MDA, BAP) and oxidative stress index in endurance horses. BMC Vet. Res. 2018, 14, 2016.

8. Capó X., Martorell M., Sureda A., Llompart I., Tur J. A., Pons A.: Diet supplementation with DHA-enriched food in football players during training season enhances the mitochondrial antioxidant capabilities in blood mononuclear cells. Europ. J. Nutrition 2015, 54, 35-49.

9. Chiaradia E., Avellini L., Rueca F., Spaterna A., Porciello F., Antonioni M. T., Gaiti A.: Physical exercise, oxidative stress and muscle damage in racehorses. Comp. Biochem. Physiol. B 1998, 119, 833-836.

10. Clarkson P. M., Thompson H. S.: Antioxidants: what role do they play in physical activity and health? Am. J. Clin. Nutr. 2000, Supplement 72, 637S-646S.

11. Deaton C. M., Marlin D. J.: Reactive oxygen species and antioxidants - a war of nutrition. Veterinary J. 2005, 169, 7-9.

12. Deaton C. M., Marlin D. J., Roberts C. A., Smith N., Harris P. A., Kelly F. J., Schroter R. C.: Antioxidant supplementation and pulmonary function at rest and exercise. Equine Vet. J. 2002, 34, 58-65.

13. De Moffarts B., Kirschvink N., Art T., Pincemail J., Lekeux P.: Effect of oral antioxidant supplementation on blood antioxidant status in trained thoroughbred horses. Veterinary J. 2005, 169, 65-74.

14. Dimock A. N., Siciliano P. D., McIlwraith C. W. Evidence supporting an increased presence of reactive oxygen species in the diseased equine joint. Equine Vet. J. 2000, 32, 439-443.

15. Ferrer M. D., Sureda A., Tauler P., Palacin C., Tur J. A., Pons A.: Impaired lymphocyte mitochondrial antioxidant defences in variegate porphyria are accompanied by more inducible reactive oxygen species production and DNA damage. Br. J. Haematol. 2010, 149, 759-767.

16. Finaud J., Lac G., Filaire E.: Oxidative Stress. Relationship with Exercise and Training. Sports Med. 2006, 36, 327-358.

17.Fisher-Wellman K., Bloomer R. J.: Acute exercise and oxidative stress: a 30-year history. Dynamic Medicine 2009, 8, 1-25.

18. Górecka-Bruzda A., Jastrzębska E., Muszyńska A., Jędrzejewska E., Jaworski Z., Jezierski T., Murphy J.: To jump or not to jump? Strategies employed by leisure and sport horses. J. Vet. Behav. 2013, 8, 253-260. 
19. Haggett E., Magdesian K. G., Maasc J., Puschnerd B., Higgins J., Fiacka C. Whole blood selenium concentrations in endurance horses. Veterinary J. 2010 186, 192-196.

20. Jaworski Z.: Ocena warunków etologiczno-hodowlanych koników polskich utrzymywanych w systemie rezerwatowym. Rozprawy i monografie 79 . Wydawnictwo Uniwersytetu Warmińsko-Mazurskiego 2003.

21. Kedzierski W., Bergero D., Assenza A.: Trends of haematological and biochemical values in the blood of young race horses during standardized field exercise tests. Acta Vet. (Beograd) 2009, 59, 457-465.

22. Kinnunen S., Hyyppa S., Lappalainen J., Oksala N., Venojarvi M., Nakao C. Hanninen O., Sen C. K., Atalay M.: Exercise induced oxidative stress and muscle stress protein responses in trotters. Eur. J. Physiol. 2005, 93, 496-501.

23. Kirschvink N., de Moffarts B., Lekeux P.: The oxidant/antioxidant equilibrium in horses. Veterinary J. 2008, 177, 178-191.

24. Kowaltowski A. J., Vercesi A. E.: Mitochondrial damage induced by conditions of oxidative stress. Free Rad. Biol. Med. 1999, 26, 463-471.

25. Lewczuk D.: The effect of sire's breed on three body measurements and body conformation score in Polish Halfbred Horse at the beginnings and on the present-day of the breed. Anim. Sci. Pap. Rep. 2005, 23, 171-179.

26. Lykkesfeldt J., Svendsen O.: Oxidants and antioxidants in disease: Oxidative stress in farm animals. Veterinary J. 2007, 173, 502-511.

27. Margaritis I., Rousseau A. S.: Does physical exercise modify antioxidant requirements? Nutrition Res. Rev. 2008, 21, 3-12

28. Marlin D. J., Fenn K., Smith N., Deaton C. D., Roberts C. A., Harris P. A. Dunster $C$., Kelly F. J.: Changes in circulatory antioxidant status in horses during prolonged exercise. J. Nutrition 2002, 132, 1622S-1627S.

29. McCusker C. A., Lamont J. V., Fitzgerald S. P.: Effect of ageing and human disease on levels of total antioxidant status. World Congress: Oxidants and Antioxidants in Biology, Santa Barbara, California 1999.

30. Metin G., Gumustas M. K., Uslu E., Belce A., Kayserilioglu A.: Effects of regular training on plasma thiols, malondialdehyde and carnitine concentrations in young soccer players. Chin. J. Physiol. 2003, 46, 35-39.

31. Miyazaki H., Oh-ishi S., Ookawara T., Kizaki T., Toshinai K., Ha S., Haga S. Ji L. L., Ohno H.: Strenuous endurance training in humans reduces oxidative stress following exhausting exercise. Eur. J. Appl. Physiol. 2001, 84, 1-6.

32. Minetti A. E., Ardigó L. P., Reinach E., Saibene F.: The relationship between mechanical work and energy expenditure of locomotion in horses. J. Exp. Biol. 1999, 202, 2329-2338.

33. Neuberg-Zuchowicz K., Geringer de Oedenberg H.: Znaczenie trenerskiej oceny naturalnych zdolności i predyspozycji koni skokowych oraz próba jej wykorzystania w szacowaniu wartości sportowej koni startujących w dyscyplinie skoków przez przeszkody. Zeszyty Naukowe Uniwersytetu Przyrodniczego we Wrocławiu, Biol. Hod. Zw. 2011, 63, 221-233.

34. Nikolaidis M. G., Jamurtas A. Z.: Blood as a reactive species generator and redox status regulator during exercise. Arch. Biochem. Biophys. 2009, 490, $77-84$
35. Paffenbarger R. S. Jr., Hyde R. T., Wing A. L., Lee I. M., Jung D. L., Kampert $J$. B.: The association of changes in physical-activity level and other lifestyle characteristics with mortality among men. N. Engl. J. Med. 1993, 25, 328, 538-545

36. Pepe H., Balci S. S., Revan S., Akalin P. P., Kurtoglu F.: Comparison of oxidative stress and antioxidant capacity before and after running exercises in both sexes. Gend. Med. 2009, 6, 587-595.

37. PietrzakS., MaciaszczykA., Pluta M.: Comparison of horse scores obtained in show jumping in national and international competitions in Poland. Annales UMCS 2014, 32, 20-28.

38. Prior R. L., Guohua C.: In vivo antioxidant capacity: comparison of different analytical methods. Free Radical Biol. Med. 1999, 27, 1173-1181.

39. Sen C. K., Packer L.: Thiol homeostasis and supplements in physical exercise. Am. J. Clin. Nutr. 2000, 72, 653S-669S.

40. Shi M., Wang X., Yamanaka T., Ogita F., Nakatani K., Takeuchi T.: Effects of anaerobic exercise and aerobic exercise on biomarkers of oxidative stress. Environ. Health. Prev. Med. 2007, 12, 202-208.

41. Sureda A., Tauler P., Aguiló A., Cases N., Fuentespina E., Córdova A. Tur J. A., Pons A.: Relation between oxidative stress markers and antioxidant endogenous defenses during exhaustive exercise. Free Rad. Res. 2005, 39, 1317-1324.

42. Taylor C. R., Maloiy G. M. O., Weibel E. R., Langman V. A., Kamau J. M. Z., Seeherman H. J., Heglund N. C.: Design of the mammalian respiratory system. III. Scaling maximum aerobic capacity to body mass: wild and domestic mammals. Respir. Physiol. 1981, 44, 25-37.

43. Toyokuni S., Okamoto K., Yodoi J., Hiai H.: Persistent oxidative stress in cancer. FEBS Letters 1995, 358, 1-3.

44. Tsai K., Hsu T., Kong C., Lin K., Lu F.: Is the endogenous peroxyl-radical scavenging capacity of plasma protective in systemic inflammatory disorders in humans? Free Radic. Biol. Med. 2000, 286, 926-933.

45. Tsuzuki N., Kanbayashi Y., Kusano K.: Markers for oxidative stress in the synovial fluid of Thoroughbred horses with carpal bone fracture. J. Equine. Sci. 2019, 30, 13-16

46. Ugras A. F.: Effect of high intensity interval training on elite athletes' antioxidant status. Sci. Sports 2013, 28, 253-259.

47. Wagner K. H., Reichhold S., Neubauer O.: Impact of endurance and ultraendurance exercise on DNA damage. Ann. N. Y. Acad. Sci. 2011, 1229, 115-123.

48. White A., Estrada M., Walker K., Wisnia P., Filgueira G., Valdes F., Araneda O. Behn C., Martinez R.: Role of exercise and ascorbate on plasma antioxidan capacity in Thoroughbred racehorses. Comp. Biochem. Phys. A. 2001, 128, 99-104.

Corresponding author: prof. dr hab. Hanna Bis-Wencel, Akademicka 13, 20-950 Lublin, Poland; e-mail: hanna.biswencel@up.lublin.pl 